\title{
TENNESSEE WILLIAMS NÃO PARECE ELE MESMO: EXPRESSIONISMO E CRÍTICA SOCIAL EM NOT ABOUT NIGHTINGALES
}

\section{Tenneessee Williams doesn't yet sound like himself: expressionism and social criticism in Not About Nightingales}

\author{
Luis Marcio Arnaut ${ }^{1}$ \\ Universidade de São Paulo - USP
}

Resumo: Analisa-se Not about Nightingales de Tennessee Williams. Escrita em uma época de acentuada crítica social na dramaturgia norte-americana, faz um contraponto com a hegemonia sobre o dramaturgo - psicologizante e autobiográfica - e revela uma dramaturgia crítica social. São analisados aspectos formais quanto à construção expressionista, evidenciando em alguns personagens o contexto histórico-crítico dos direitos humanos.

Palavras-chave: Tennessee Williams; Teatro norte-americano; Not about Nightingales.

Abstract: It is analyzed Not about Nightingales by Tennessee Williams. Written in a time of marked social criticism in American dramaturgy, it counteracts the hegemony over the playwright - psychological and autobiographical - and reveals a critical social dramaturgy. Formal aspects of expressionist construction are analyzed, highlighting in some characters the historical-critical context of human rights.

Keywords: Tennessee Williams; American Theater; Not about Nightingales.

1 Doutorando em Teoria e Prática do Teatro na Escola de Comunicação e Artes da Universidade de São Paulo - ECA USP. 


\section{O Drama de Tennessee Williams}

A obra de Tennessee Williams (1911-1983) é associada a uma tradição norteamericana de drama familiar. Por isso, apresenta-se um grande desafio abordar sua dramaturgia como uma análise do "macrocosmo da sociedade de classe média americana a partir do espaço individual" (BETTI, 2007, p. 2). Todavia, as apreciações crítica e pública sempre preferem o foco familiar. Além, disso, é importante ressaltar que, no contexto brasileiro, as escassas traduções de suas obras completas, especialmente a ausência das traduções de seus trabalhos inéditos no país, dificultam ainda mais discutir a presença e a importância de uma perspectiva crítica na representação de questões sociais em sua dramaturgia como um todo. $O$ que se vê são encenações e estudos focados apenas nas peças mais famosas, um volume bastante pequeno perante a coleção completa do autor.

O passo decisivo na direção de novas leituras do trabalho de Tennessee Williams, entretanto, é o de enfrentar o desafio de reler seus trabalhos na contramão da crítica dominante, que o desbastou de tudo o que não fosse condizente com as balizas estabelecidas em torno de sua canonicidade e do padrão biográfico de interpretação que lhe foi aplicado. (BETTI, 2012, p. 26)

A proposta aqui é observar a obra do autor além destas questões tradicionalmente assinaladas, o que vem a ser, portanto, uma investigação que descortina não apenas as proporções experimentais na forma dramatúrgica de uma obra não canônica, Not about Nightingales, mas também, uma clara evidência de um retrato historicizante de cicatrizes sociais e políticas que fazem um recorte da sociedade. Dispõe-se, portanto, a investigar os elementos que não estão alinhados com a visão hegemônica de sua obra que privilegia a autobiografia e o psicologismo, ainda que concernentes, mas não como componentes categóricos.

\section{Tennessee Williams Não Parece Ele Mesmo em Not about Nightingales}

Tennessee Williams escreveu Not about Nightingales, peça em três atos, em 1938. A peça é fruto de suas impressões sobre um caso real de tortura de 200 prisioneiros que haviam entrado em greve de fome como forma de protestar contra os maus tratos aos quais eram submetidos em uma penitenciária na Pennsylvania, resultado do cerco brutal das autoridades, que ainda teve como consequência a morte de quatro homens.

Devido ao formato muito extenso, aproximadamente três horas de duração, o número elevado de personagens e as dificuldades financeiras para produzi-la, ela não foi encenada. Talvez, o que tenha impedido, de fato, que viesse a ser produzida e tornando-a intocável por sessenta anos, viria a ser o seu tom extremamente crítico-social que não está alinhado com a leitura tradicional e hegemônica de suas major plays, somando-se com a grande ojeriza do sistema capitalista em sofrer críticas e questionamentos. Suas outras peças longas desta época também são obstruídas e negligenciadas, pois apresentam, 
igualmente, preocupação social, escritas neste mesmo tom.

Not about Nightingales teve sua estreia mundial apenas em 1998, em Londres, após a atriz Vanessa Redgrave (1937-) redescobri-la. Esta encenação foi considerada um grande acontecimento por se tratar de uma obra de Tennessee Williams jamais encenada e, também, pela atenção ao ativismo da atriz britânica e sua histórica luta antifascista. Segundo Bernard (2005, p. 1), a montagem chegou a chocar e surpreender muitos críticos e acadêmicos por ser tão diferente daquilo que, até então, costumeiramente era chamado de "estilo do autor". Na verdade, a crítica e o público demonstram um anseio plangente em encontrar somente reproduções de suas major plays e não um autor crítico do sistema político-social. Com isso, o dramaturgo é rechaçado e duramente repudiado, tal como aconteceria posteriormente com suas late plays. Hornby (1999, p. 284, tradução nossa) afirma que é uma grande calamidade a peça não ter sido montada antes, devido ao seu "valor estético e sua crítica social".

Not about Nightingales, cujo primeiro título atribuído pelo autor era Hell, an Expressionistic Drama (Inferno, um Drama Expressionista, em tradução livre), possui 23 personagens e é a terceira peça longa escrita por Tennessee Williams. Apresenta uma abordagem profundamente lírica ao retratar a violência e a luta dos presidiários por direitos humanos. Mostra um outro Tennessee Williams, ampliando a compreensão de sua obra para uma dimensão expressionista, o que dinamiza a sua postura política e crítica.

O título é retirado do poema Ode to a Nightingale, de John Keats (1795-1821), um dos últimos poetas românticos ingleses, que é declamado em uma cena da peça pelo personagem Jim. $O$ enredo gira em torno de um grupo de presidiários comandados pelo personagem Butch O'Fallon, caracterizados pela resistência às investidas violentas e duras do diretor da prisão Boss Warden. A prisão está localizada em uma ilha, construída sobre pedras, o que impossibilita a fuga. Diante das imposições restritivas e abusivas do diretor, o grupo decide por uma greve de fome, o que causa sua ira e confinamento em uma sala de tortura chamada Klondike. Apenas Butch sobrevive e, ao final, vingase do diretor juntamente com Jim - ambos acabam se tornando anti-heróis para lutar contra uma natureza violenta a que são submetidos. Entremeios, há o romance de Eva e Jim, considerado por Butch um traidor, porque delataria ao diretor tudo que era dito nas celas. A moça, sofrendo com as dificuldades de emprego causadas pela Depressão, é contratada como secretária de Warden, que a assedia sexualmente. A relação amorosa progride no desenrolar da peça, mas não se consuma de fato. Butch mata Warden e Jim se joga na baia, na esperança de fugir dali. Vários personagens aparecem e desaparecem e deixam a evidência dos contextos de sua posição social e política na sociedade norte-americana naquela época, como: mulheres, homossexual, negro, líderes religiosos, além da posição da maioria dos 
personagens como presidiários

(WILLIAMS, 1998).

\section{O Expressionismo na Dramaturgia de Tennessee Williams}

Há um pareamento da realidade, fatos e pessoas, com a ficção em Not about Nightingales e a sua representação remete à estética expressionista.

É possível que a personagem Jim seja inspirada no ator Jules Garfield (19131952), que fora ator do Group Theatre, conhecido grupo de esquerda em Nova York. $\mathrm{O}$ ator já tinha atuado em duas peças de cunho social do engajado dramaturgo Clifford Odets (1906-19630. Nas passagens líricas de Jim, que trazem 0 discurso sarcástico de sua classe trabalhadora, os monólogos trazem referências ao encarceramento e o poder das rebeliões. Quando Jim declama 0 poema de Keats, Tennessee Williams indica que o prisioneiro deve se tornar um ativista. $\mathrm{O}$ monólogo chave de Jim sobre a culpa no último episódio do Ato Dois mostra que o homem não tem livre arbítrio, portanto não tem culpa. Curiosamente, este foi o argumento que o advogado Clarence Darrow (1857-1938) usou no caso LoebLeopold $^{2}$, alegando que esses homens eram um produto de três fatores sobre os quais eles não têm controle:

\footnotetext{
2 Nathan Freudenthal Leopold, Jr. (1904-1971) e Richard Albert Loeb $(\underline{1905}-\underline{1936})$, mais conhecidos como "Leopold e Loeb", foram estudantes da Universidade de Chicago que assassinaram o garoto Bobby Franks, de 14 anos de idade, em 1924, e foram sentenciados à prisão perpétua. Em sua defesa, eles afirmaram ter matado o garoto apenas pela vontade de cometer um crime perfeito. Quando presos, os dois contrataram Clarence Darrow para ser seu advogado de defesa (BAATZ, 2008).
}

hereditariedade, meio ambiente e a falta de chance na sociedade. Tennessee dedicou sua peça a este advogado, aclamado como o campeão das causas perdidas.

JIM (Voz sufocada): Que lugar é este?
Pra que serve? Por quê? Os juízes
dizem culpado. Mas o que é culpado?
O que essa palavra significa? É
engraçado, mas não sei. (Pega o
dicionário) O Dicionário diz:
"Responsável por cometer um crime."
Mas por que responsável? O que
significa responsável? Quem teve uma
chance? Quando eles juntam nossas
moléculas, eles perguntam
educadamente a cada uma delas se
vai ser homem rico, homem pobre,
mendigo, ladrão? Claro que não! É
tudo acidental. E ainda assim o juiz
fala, "Jim, você é culpado!" (Joga o
dicionário no chão) Este livro não tem
mais tanto valor. Precisamos de outro,
com novas definições. (WILLIAMS,
1998, p. 103-104, tradução nossa)

Em Not about Nightingales há assassinato, violência e dois personagens, no mínimo, diferentes para os padrões dramatúrgicos da época: o negro simpático, que tem sua fala escrita conforme é dita, e uma travesti sifilítica marcam não só as dificuldades de sua encenação naquela época, mas inovações formais de uma dramaturgia que pretendia mostrar a sociedade com personagens emblemáticos.

O teatro expressionista de Tennessee vem opor-se à reprodução autêntica desta realidade em que se baseia, de forma a renunciar a imitação do mundo exterior e concentrando-se em refletir a essência das coisas através de uma visão idealizada do ser humano: os prisioneiros são pessoas que lutam por um lugar ao sol. A 
expressividade é apresentada da forma mais forte possível, de modo a atingir diretamente o público, fazendo que cada elemento presente na cena se comunique diretamente. Está no despertar das personagens e na dramatização de seus sentimentos. Além disso, toda a peça é narrada em episódios que se alinhavam entre si, justapondo-se um acontecimento nas celas e outro no escritório do diretor da prisão, intercalando-os. Tudo que se vê, portanto, é a luta contra os valores burgueses e a autoridade estabelecida. Mostra-se revolucionário evidenciar um grito de liberdade, de direitos humanos e deveres do Estado. Em comparação direta com o sofrimento exagerado e quase grotesco do quadro $O$ Grito de Evard Munch (1863-1944), Not about Nightingales traz em suas personagens enclausuradas a identificação deste grito de horror, sobre a iniquidade e o estanque. Os personagens gritam, de forma a buscar a greve de fome, única expressão radical de que dispõem. Cada personagem tem seu nome, suas facetas e características, mas é visto como parte de uma massa pelo diretor da prisão, destituído de identidade ou com identidade fragmentada, sendo-lhe são negadas transformações. Os personagens são, portanto, marionetes do sistema carcerário, da visão extremista do fascismo do diretor e reducionista quando cotejam a mulher, 0 homossexual, o negro, o judeu e o imigrante - personagens que se perdem simbolicamente sob o efeito da sociedade que impõe padrões, preconceitos e normas.
A cena da morte na Klondike de quase todos os personagens é emblemática e evidencia o expressionismo, quando aborda a tragédia no contraponto de Butch cantando, expondo seus sentimentos com uma necessidade premente de reflexão do espectador sobre a violência e a morte:

BUTCH: Joe! Ei, Joe! Swifty! Você aí, Rainha! Shapiro! (Puxa um dos corpos) Vamos cantar! Vamos cantar juntos alguma coisa! Vamos cantar alto! Alto!

For-tune`s always hid-ing! Por que vocês não cantam alguma coisa, seus desgraçados! Vamos lá cantem! Cantem!

I looked ev'rywhere -!

(WILLIAMS, 1998, p. 115, tradução nossa)

\section{Os Presidiários e Boss Warden}

Investiga-se aqui a relação dos presos com os funcionários da prisão. É importante frisar a representatividade que o diretor Boss Warden carrega na peça: a imagem americana do homem branco de classe média patriarcal, tornando-se, assim, um reflexo da camada dominante da época. Por isso, essa relação de opressor e oprimido fica tão evidente. Principalmente, quando Warden se utiliza da tortura como instrumento de vingança e intimidação com o propósito de castigar, punir quem ameaça a ordem interna e os que afrontam os detentores do poder.

DIRETOR: Está vendo essas cicatrizes, Eva? Elas já têm dez anos. Ele tinha boa aparência na época. Ficou em carne viva. A pele rasgava e ficava pendurada nas costas, igual bacon! $O$ sangue jorrava que nem 
suco de tomate toda vez que eu chicoteava. "Já chega, Jim? Vai voltar para a máquina de estampagem?" "Não", ele respondia, "ela está quebrada!" Resistiu por catorze dias. Ou eu matava ou admitia a derrota. Falei: "Jim, você venceu! Não precisa voltar para a máquina de estampagem, fica aqui no escritório. Vai trabalhar para mim porque você é feito do material que eu gosto!" Rosto de pedra. Hein, Jim? (WILLIAMS, 1998, p. 58, tradução nossa)

Diante de um Estado que não cumpre o dever essencial de proteger o cidadão do mal causado por terceiros e sem poder confiar na ação morosa da Justiça, a sociedade entrega com grado às forças de repressão a tarefa de castigar. Somando o fato de que profissionais mal pagos e, muitas vezes despreparados para a função, adotam indiscriminadamente a estratégia mais rápida para corrigir e obter confissões.

DIRETOR: Não vou tolerar greve de fome aqui dentro. O país fica comovido. E depois? Aparecem esses defensores de direitos humanos para reclamar do tratamento que damos a esses bandidos que esfaqueiam a própria mãe para roubar dinheiro de cerveja!

JIM: A maneira mais fácil de evitar a greve é dar alimentação melhor.

DIRETOR: Evitar a greve, uma merda! Eu vou é meter o pé nisso! Espera até eles verem o pessoal que está na solitária. Se não for suficiente isso, a gente esquenta eles! (Sai)

JIM: Esse homem é louco. É o próprio Mussolini. (WILLIAMS, 1998, p. 71, tradução nossa)

No entanto, a pobreza em que vivia boa parte dos americanos, preponderantemente os negros e latinos, o contraste com a opulência dos bem-sucedidos e a agravante discriminação racial, não são as únicas causas, mas contribuem decisivamente para a disseminação da violência urbana e exclusão social, doenças que se tornam epidêmicas quando atingem as classes mais desfavorecidas. Diante de uma clara hierarquia liderada pelos mais fortes, encabeçada pelo diretor, desenvolvendo-se pelos outros funcionários e até entre os presos, Not about Nightingales também serve como um espelho de uma sociedade cultivadora da relação entre opressor e oprimido, reproduzida no mais alto escalão econômico e entre os mais miseráveis e indefesos (HALE, 1999). Como nos momentos em que Ollie, personagem negro com nenhuma escolaridade, é induzido a prestar favores a Jim influenciado por um complexo de serventia e ingenuidade. Há que se notar que Tennessee Williams reproduz na fala deste personagem a semântica que representa a forma de falar do seu grupo social nos Estados Unidos.

\section{Senhora Bristol e Eva}

A Senhora Bristol, quando busca o filho na prisão, que ela acredita ser inocente, retrata-se a Warden de forma insistente e penitente, desesperada, querendo ver o filho, para lhe entregar um bolo ou dizendo que ele não deveria mesmo estar preso. A reação do diretor da prisão é de total descaso, lacônica, ignorando a voz feminina, tal como a visão machista que não ouve as reinvidicações de igualdade e expressividade da mulher.

SENHORA BRISTOL: Ele era tão intransigente, até mesmo com 0 
coitado do Jack, que saiu de casa. Contra minha vontade, mas ... (Abre a bolsa e exibe um maço de cartas) Ah, ele escreveu cartas maravilhosas! Se o senhor lesse, ia ver que ele é um menino excepcional. Porto Said, Marseilles, Cairo, Shangai, Bombaim! Ele sempre escrevia: "Mãe, é tão grande, tão grande". Acho que ele tentou guardar tudo aquilo no coração e não coube, seu coração explodiu! Olha esses envelopes! Quase não dá pra fechar! Fotos dos lugares também! Elefantes na Índia. Lá eles usam elefantes como cavalos de carga, pro trabalho comum. [...] Eu sempre escrevia pra ele: "Jack, essa vida não tem futuro. Um marinheiro sempre vai ser um marinheiro. Sai dessa vida, filho. Entra no Serviço Público!". Ele me respondeu: "Noite passada fiquei de guarda. Aqui dá pra ver mais estrelas do que no norte. [...]Depois de um tempo sem escrever - chegou essa. Não entendo! Ele mencionou uma garota. Disse que não foi culpa dele, eu sei que não foi - se eu pudesse convencer o senhor disso! DIRETOR: Não adianta, madame! A senhora pode falar até com a lua. Ele teve a chance dele.

(WILLIAMS, 1998, p. 35-36, tradução nossa)

Com o personagem Eva, todavia, é possível identificar que Williams critica os estereótipos da mulher e suas restrições sexuais e sociais, exprimindo historicamente sua condição na composição da personagem, desconstruindo o mito feminino. Desta forma, desmistifica as virtudes que eram exigidas: beleza, passividade, submissão, virgindade e assexualidade. Ela é uma mulher que busca um emprego, tem a coragem de se candidatar a uma vaga em uma ilha isolada onde só há homens, mesmo que isso seja uma imposição das necessidades econômicas da Depressão, mas revela aí uma mulher com uma característica que se mostra aquém da feminilidade frágil, reprimida e submissa. Quando é assediada por Warden, ela se mostra paradoxalmente inclinada a ceder, revelando sua feminilidade e a coragem de aceitar seus desejos e pulsões.

\section{Rainha}

O personagem gay na obra de Tennessee Williams é "irrepresentável em seu tempo" (BETTI, 2007, p. 152). Em Not about Nightingales, o dramaturgo, todavia, expõe a maneira como a homossexualidade é considerada na década de 1930: preconceituosa, repressora, autodestrutiva e homofóbica. Dá voz a um homossexual assumido, travestido e que traz toda a simbologia da cultura gay, retratando-a inserido em meio ao grupo de prisioneiros masculinos como um forasteiro, excêntrico, pessoa ameaçada, oprimido e como um alívio cômico, claramente invocando a forma épica.

A abordagem da homossexualidade aqui por Tennessee Williams abarca essa conjuntura social e política. Williams salienta, assim, a necessidade do tema tabu como uma forma de denunciar e mostrar as consequências da opressão e manipulação da sociedade heteronormativa.

A personagem tem por nome Queen, cuja tradução é Rainha e é utilizada na gíria norteamericana para denominar o homossexual que se destaca entre os demais. Talvez, aos olhos contemporâneos, a personagem pode 
ser compreendida como uma travesti por conta da sua caracterização.

Rainha, embora inserida entre os demais personagens, tenta dialogar, mas não há respostas. Sua participação nos diálogos é quase que uma caracterização monológica, sendo absolutamente ignorada pelos outros personagens, o que vem denotar como a masculinidade pretende tratar as relações homossexuais.

RAINHA: Onde está meu estojo de manicure?

BUTCH: Será que a gente ainda dá no couro com sessenta anos.

JOE: Como assim?

BUTCH: Prá pegar as mulheres.

JOE: Ah, depende da pessoa.

BUTCH: Eu vou estar bem ainda. Mas vinte anos é muito tempo pra esperar.

RAINHA: Alguém viu meu estojo de manicure?

BUTCH: Sabia que tem uma janela no escritório do diretor que dá pra baía?

(WILLIAMS, 1998, p. 32, tradução nossa)

\section{Capelão e Reverendo}

A cultura da corrupção é mostrada por Tennessee nos personagens religiosos, Chaplain e Reverend Hooker (Capelão e Reverendo Hooker), aprofundando uma crítica à instituição religiosa. Warden tenta convencer Chaplain a se curvar aos seus mandos e exigências. $O$ capelão se mostra um homem ético, certamente buscando os direitos humanos, uma voz que lutaria em defesa dos criminosos sob a opressão do poder, que tira deles as chances de restabelecimento e nova inserção na sociedade. Deixa claro, portanto, a ineficiência do sistema carcerário que investe na violência e na obediência:
"CAPELÃO: Sou um servo consciente sobre Cristo e, como tal, protesto contra o tratamento desumano dado aos detentos nesta prisão! DIRETOR (Levanta rápido) Quem está dirigindo esta prisão, o senhor ou eu?" (WILLIAMS, 1998, p. 85, tradução nossa). O capelão tem consciência de que a religião é um fenômeno estruturado, mas também estruturante da realidade social e da moralidade dos indivíduos ali encarcerados

Williams expressa através do Reverend Hooker a saturação do sistema, que vê na coerção moral uma forma de transgredir até os direitos de ter uma crença religiosa. Desta forma, Warden contribui ainda mais para a degradação pessoal e social, pelo evidente desrespeito ao princípio da dignidade humana. O personagem faria, portanto, uma preparação psicológica dos prisioneiros para a ida à Klondike e, ao mesmo tempo, incutindo medo e pavor, a fim de torná-los dóceis e obedientes. O reverendo obedece, então, o diretor da prisão sem questionar.

A intenção de Warden, portanto, seria criar um grupo que aceitasse o processo de exploração sem reivindicar seus direitos, desde que a religião cristã que ele impõe aos encarcerados ensina que o fiel deve se dedicar ao trabalho e à moral como aspetos determinantes do bom religioso - 0 homem de bem -, portanto, é legítima a compreensão de que a religião é um instrumento de conservação da ordem, mas também de opressão, e que a figura de um líder religioso é de suma importância para o indivíduo como ser político, pois ele influencia nas subjetividades.

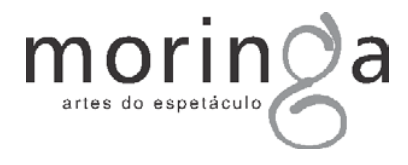


DIRETOR: É, bom, quero que aceite esta nota de cinco, reverendo.

REVERENDO: E o choque nervoso?! Minha nossa!

DIRETOR: Hein? Bom - [...]

DIRETOR: Tome mais dois dólares.

(WILLIAMS, 1998, p. 91, tradução nossa)

\section{A Descoberta de um "Outro" Tennessee Williams}

A estética realista e/ou naturalista ainda domina 0 imaginário da população, principalmente quanto ao artificialismo e o fabricado. Isto fortalece consideravelmente a visão hegemônica sobre a dramaturgia de Tennessee Williams, supervalorizando a construção dos personagens, seus desejos, paixões, pulsões sexuais, conflitos e contradições, quando se considera que 0 dramaturgo retrata apenas os comportamentos individuais, como pensam, agem, suas relações emocionais e familiares, a partir de aspectos freudianos. Porém, distancia-se de outras leituras igualmente, senão mais importantes, do contexto da sua obra.

A robustez do texto de Not about Nightingales reside nas condições sóciohistóricas que, ao embrenhá-las, ficam evidentes e toda a dinâmica faz parte da cena. Williams aqui é, portanto, um dramaturgo mais consciente de sua posição política e não apenas um dramaturgo realista ou psicológico, como teima a canonicidade. Tennessee Williams não parece ele mesmo, portanto, nesta peça, porque não está irradiando a ideia hegemônica de sucesso comercial.
Com um retrato das personagens de Not about Nightingales, confinadas em um enredo que não apresenta solução senão na violência e no confronto inevitáveis, Williams faz de cada elemento cênico, do ator, do cenário, da luz e da música (extensivamente usada em diversas cenas), um elemento de choque, portador do grito silencioso dos oprimidos.

A peça se comunica com a contemporaneidade no que diz respeito à crítica social, aos aspectos históricos, políticos e sociais que são tratados pelo autor. Isto porque é possível confrontar, ainda nos dias de hoje, as discussões infindáveis sobre a forma como a sociedade norte-americana era na década de 1930. Por conta destas questões, a peça traz reflexões sobre os direitos humanos, o fascismo e a espetacularização da tragédia.

Reconhece-se claramente que a forma dramatúrgica tradicional realista e psicológica, em que se enquadrou Tennessee Williams, historicamente não conseguiria exprimir a crítica sócio-política que Not about Nightingales expõe cruamente e que ao expressionismo serviu para tornar tal estética inovadora no contexto estadunidense da década de 1930 e, posteriormente, nos anos de 1990 quando a peça foi finalmente trazida aos palcos.

Recebido em 21/04/2018

Aceito em 15/08/2018 


\section{Referências Bibliográficas}

BAATZ, Simon. Leopold and Loeb's Criminal Minds. In: Smithsonian Magazine. Agosto, 2008. Disponível em: https://www.smithsonianmag.com/history/le opold-and-loebs-criminal-minds-996498/. Acesso em 05/12/2017.

BERNARD, Mark. Punishment and the Body: Boss Warden, Michel Foucault, and Not About Nightingales. In: The Tennessee Williams Annual Review, No 07, 2005. Disponível em: http://www.tennesseewilliamsstudies.org/journal /work.php?ID=59. Acesso em 16/10/2017.

BETTI, Maria Silvia. Alegoria Política e Representação em Camino Real, de Tennessee Williams. In: CHAIA, M. (org). Arte e política. São Paulo, Programa de Estudos Pós-graduados em Ciências, 2007.

BETTI, Maria Silvia. Lirismo e Ironia: Apresentação. In: Williams, T. 27 Carros de Algodão e Outras Peças em Um Ato. São Paulo: É Realizações, 2012. p. 7-26.

HALE, Allean. Not about Nightingales: Tennessee Williams as Social. In: Modern Drama, Vol. 42, No 03, Outono. 1999. p. 346-362. Disponível em: https://muse.jhu.edu/article/499998/pdf. Acesso em 23/08/2017.

HORNBY, Richard. Williams and Miller on Broadway. In: The Hudson Review, Vol. 52, No. 2, Verão, 1999, pp. 282-288. Disponível em: http://www.jstor.org/stable/3853421. Acesso em 17/10/2017.
WILLIAMS, Tennessee. Not about Nightingales. Ed. Allean Hale. Nova Iorque: New Directions, 1998.

WILLIAMS, Tennessee. Não Será Sobre Rouxinóis. Augusto César (trad.). (digitado). 2018. 